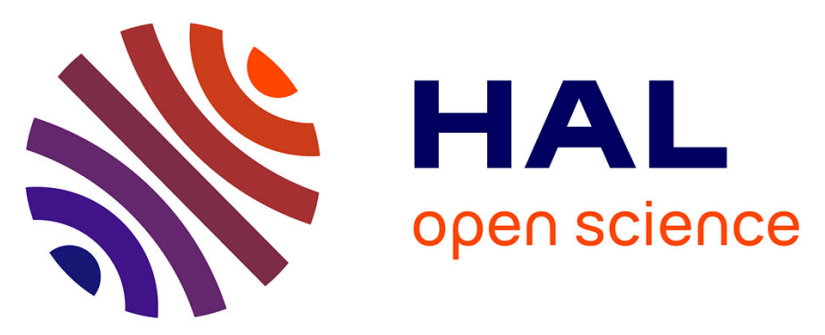

\title{
Tellurite glass thin films on silica and polymer using UV (193nm) pulsed laser ablation
}

\author{
Zhanxiang Zhao, Gin Jose, Paul Steenson, Nikos Bamiedakis, Richard V \\ Penty, Ian H White, Animesh Jha
}

\section{- To cite this version:}

Zhanxiang Zhao, Gin Jose, Paul Steenson, Nikos Bamiedakis, Richard V Penty, et al.. Tellurite glass thin films on silica and polymer using UV $(193 \mathrm{~nm})$ pulsed laser ablation. Journal of Physics D: Applied Physics, 2011, 44 (9), pp.95501. 10.1088/0022-3727/44/9/095501 . hal-00599245

\section{HAL Id: hal-00599245 \\ https://hal.science/hal-00599245}

Submitted on 9 Jun 2011

HAL is a multi-disciplinary open access archive for the deposit and dissemination of scientific research documents, whether they are published or not. The documents may come from teaching and research institutions in France or abroad, or from public or private research centers.
L'archive ouverte pluridisciplinaire HAL, est destinée au dépôt et à la diffusion de documents scientifiques de niveau recherche, publiés ou non, émanant des établissements d'enseignement et de recherche français ou étrangers, des laboratoires publics ou privés. 


\title{
Tellurite glass thin films on silica and polymer using UV $(193 \mathrm{~nm})$ pulsed laser ablation
}

\author{
Zhanxiang Zhao ${ }^{1}$, Gin Jose ${ }^{1 *}$, Paul Steenson ${ }^{2}$, Nikos Bamiedakis ${ }^{3}$, Richard V \\ Penty $^{3}$, Ian H White ${ }^{3}$ and Animesh Jha ${ }^{1 *}$ \\ ${ }^{1}$ The Institute for Material Research, Houldsworth Building, Clarendon Road, \\ The University of Leeds, Leeds, LS2 9JT, UK a.jha@leeds.ac.uk and \\ g.jose@leeds.ac.uk \\ ${ }^{2}$ The School of Electronic and Electrical Engineering University of Leeds, Leeds, \\ LS2 9JT, UK \\ ${ }^{3}$ Electrical Engineering Division, Department of Engineering, University of \\ Cambridge, 9 JJ Thomson Avenue, Cambridge, CB3 0FA, UK
}

\begin{abstract}
Erbium doped tellurite glass thin films were deposited using excimer (193 nm) laser ablation onto two different types of substrates: silica and polymer-coated silica for engineering optical integrated active-passive devices. The deposition conditions were optimized for both substrates in order to produce high quality rare-earth $\left(\mathrm{Er}^{3+}\right)$ ion doped glass thin films with low propagation loss. The optical and spectroscopic properties of the deposited films, namely transmittance, fluorescence, lifetime as well as refractive indices at $633 \mathrm{~nm}$ were measured and analyzed in detail.
\end{abstract}

Key words: Tellurite glass, pulsed laser deposition (PLD), thin films, siloxane polymer, PDMS

* Corresponding author 


\section{Introduction}

Siloxane polymers are promising materials for passive optical device engineering for applications in optical communication systems due to their high optical transparency and low Rayleigh scattering in the 800-1500 nm wavelength range [1]. These materials exhibit excellent thermal and mechanical properties [2], and over the last 20 years siloxane polymers have been specially engineered for low transmission loss passive and active optical devices, with a range of molecular and physical properties making them structurally compatibility with inorganic substrates. The key passive applications of components fabricated using such films are add/drop multiplexers in arrayed waveguide grating (AWG) geometries, and signal splitters for multichannel transmission with the main active application being thermo-optic and electro-optic switching [3]. The present siloxane polymers exhibit low loss in waveguide structures $(<0.1$ $\mathrm{dB} \mathrm{cm}^{-1}$ ) at the common communication wavelengths of $840 \mathrm{~nm}, 1310 \mathrm{~nm}$, and 1530-1620 nm, and have recently been demonstrated in athermal AWG devices that meet the Telecordia specifications [3, 4].

Siloxane polymer waveguides also have the potential for use in the backplane of personal computers (PC) in the data communication circuits. In high-speed data communication systems operating around $840 \mathrm{~nm}$ and in optical communication networks (1310 nm and 1530-1620 nm), the attenuation of signal power can be quite significant due to coupling losses, linear and polarization related losses, and the diffraction loss in AWGs. This means that the multi-wavelength signals must be amplified for optimum performance, requiring active functionality in the polymer based integrated devices. One of the limitations of siloxane and related polymer structures in integrated optical devices at present is their reliance on fluorescent dye molecules for light amplification to compensate the loss of signal power. The dye molecules when incorporated in polymer matrix have the disadvantage of fluorescence quenching making it impossible to produce continuous wave $(\mathrm{CW})$ gain. Moreover, the dye molecules age with laser irradiation and, consequently, the amplification process suffers adversely, reducing the lifetime of the component. However, the authors are studying a possible alternative, where, in place of the dye molecules for light amplification, a combined hybrid rare-earth ion-doped glass structure and polymer is used. In this respect the work discussed herein builds upon that of others, such as Pun and coworkers, who studied $\mathrm{Er}^{3+} / \mathrm{Yb}^{3+}$ co-doped polymers for amplifying gain medium engineering[5]. Quang et al. employed an erbium doped complex in a polymer matrix for increasing doping concentrations [6], and Yang et.al recently demonstrated a waveguide amplifier using $\mathrm{Nd}^{3+}$ ions doped polymer complex material [7]. The main objective of the work presented in this paper is to provide an alternative route to light amplification in polymer waveguides, via the integration of the polymer and rare-earth doped glass thin films.

$\mathrm{TeO}_{2}$ glasses exhibit large solubility for rare-earth ions [8], which is why this glass host was chosen for forming the thin films. The glass host is also amenable to femtosecond pulsed laser deposition, as originally demonstrated by Jose and co-workers [9]. Presently however, there are no reported results for 
the PLD deposition of rare-earth doped thin films, or patterned glass waveguide fabrication, on siloxane polymer coated silica substrates, and this is the motivation for the work reported here. Such doped glass structures incorporated on polymers will be a suitable gain block in a polymer-glass integrated device. The glass thin films were prepared using $193 \mathrm{~nm}$ pulsed laser deposition (PLD), which preserves the stoichiometry of the deposited films, compared to that of the source glass. The PLD approach also favors high deposition rates ( $\mathrm{Hz}$ to $\mathrm{kHz}$ pulse repetition rate) and composite/multi-target / material deposition,

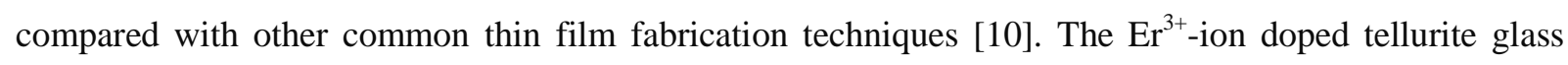
films were fabricated on both silica and polymer coated silica substrates, and the deposition parameters were optimized for both substrates. Subsequently, the thin films were characterized for their optical and spectroscopic properties.

\section{Experiments}

In this work, tellurite tungsten lanathanum (TWL) glass targets were the source material for the PLD system. The composition of these targets was optimised for this fabrication process and consists, in weight percent (wt $\%$ ) of $60-\mathrm{TeO}_{2}, 20-\mathrm{WO}_{3},(20-\mathrm{x})-\mathrm{La}_{2} \mathrm{O}_{3}$, where $\mathrm{x}$ is weight percentage of $\mathrm{Er}_{2} \mathrm{O}_{3}$. Although the value of $\mathrm{X}$ can be increased significantly to several wt\%, in this work, the percentage of $\mathrm{Er}_{2} \mathrm{O}_{3}$ was limited to $1 \mathrm{wt} \%$ to minimize the effects of concentration quenching and ion-ion crossrelaxations in the $\mathrm{Er}^{3+}$-ion waveguide structures. All precursor chemicals were better than $99.998 \%$ pure whereas the purity of rare-earth oxides was limited to only $99.99 \%$. The constituent oxides were mixed and ground using a mortar and pestle inside a dry glove box and then transfered into an alumina crucible, which was then placed inside a muffle furnace maintained at $975^{\circ} \mathrm{C}$. The crucible was held at $975^{\circ} \mathrm{C}$ for 2.5 hours in a dry oxygen atmosphere with the flow rate of $1 \mathrm{~L} / \mathrm{min}$ for melting and homogneization purposes. Subsequently, the melt was cast into a polished bronze mould preheated at $400^{\circ} \mathrm{C}$. The quenched liquid formed glass which was then left to anneal at $430^{\circ} \mathrm{C}$ for $3 \mathrm{hrs}$, after which it was allowed to cool down to room temperature at a rate of $0.5{ }^{\circ} \mathrm{C} / \mathrm{min}$. The high melting temperature of the glass do not favour the use of gold crucible, while a platinum crucible undergo corrosion on melting the glass with chemical composition reported above.

The glass samples prepared were polished and their thermal properties were studied using differential thermal analysis (DTA). The results showed that the $\mathrm{T}_{\mathrm{g}}$ and $\mathrm{T}_{\mathrm{x}}$ of the glass were $438^{\circ} \mathrm{C}$ and $610^{\circ} \mathrm{C}$, respectively, which indicates that the glass has excellent thermal properties.

The prepared target was mounted in the target holder inside a custom-built pulsed laser deposition chamber, equipped with a $193 \mathrm{~nm}$ excimer with $20 \mathrm{~ns}$ pulse duration source. The substrate material was placed vertically above the target with a separation of $50 \mathrm{~mm}$. The pulsed laser was focused on the target with the fluence of $1.3 \mathrm{~J} / \mathrm{cm}^{2}$ and a repetition rate of $10 \mathrm{~Hz}$. Prior to deposition the PLD chamber was 
pumped down to less than $10^{-6}$ mTorr, and then filled with high purity process gases $\left(\mathrm{O}_{2}\right.$ or $\left.96 \% \mathrm{O}_{2}: 4 \% \mathrm{He}\right)$ at a rate of $20 \mathrm{sccm}$, whilst continuing to pump in order to maintain a residual pressure of 135 mTorr. During the deposition experiments, a range of temperatures between room temperature and $400^{\circ} \mathrm{C}$ were tried. However, for the active-passive waveguide integration with siloxane polymer coated silica substrate, we focused on two temperature limits: one at $100^{\circ} \mathrm{C}$, which is close to the glass transition temperature $\left(\mathrm{T}_{\mathrm{g}}\right)$ of polydimethyl siloxane (PDMS), and the other at $300^{\circ} \mathrm{C}$, above which the polymer degradation due to thermal decomposition becomes significant. The thickness of the siloxane layer on silica was $\sim 25 \mu \mathrm{m}$. Since the $\mathrm{T}_{\mathrm{g}}$ of the TWL glasses are in the range of $420^{\circ} \mathrm{C}$ to $450^{\circ} \mathrm{C}$, and for better structural compatibility and stress management between the three dissimilar materials (PDMS, TWL, and the silica substrate) the higher substrate temperature for the film deposition was considered preferable, in the first instance, which is why we chose to start with a $300^{\circ} \mathrm{C}$.

The transmittance and fluorescence of the TWL-PLD films were measured with an Ultraviolet-visibleNIR spectrometer, Lambda 19 (Perkin Elmer) and a Spectro-fluorimeter (Model FS 920, from Edinburgh Instruments, UK) respectively, while a Metricon prism coupler (model 2010) was employed for measuring the refractive index, thickness and propagation loss of the films at $633 \mathrm{~nm}$. The compositions of the bulk glasses and the thin films were investigated using energy dispersive X-ray analysis (EDX) and the XRD. The surface topography of the deposited films was examined using a LEO 1530 field-emissionscanning electron microscope (FEG SEM). All these measurements were repeated after three months of preparing and the results were remained unchanged showing stability of the structures for such durations.

\section{Results and discussion}

The compositions of the target glass and the thin films obtained using EDX are listed in table 1 in atomic\%. The EDX data of the samples show 2.71 atomic\% aluminum $\left(\sim 0.7 \mathrm{~mol} \% \mathrm{Al}_{2} \mathrm{O}_{3}\right)$ introduced in the target glass due to the use of an alumina crucible for glass melting. Varying concentrations of $\mathrm{Al}$ are present in the thin films reported in the table. Being a glass former, the presence of $\mathrm{Al}_{2} \mathrm{O}_{3}$ in such small concentrations will not detrimentally affect the optical and spectroscopic properties of the glass. The XRD of the target glass and thin films prepared under different conditions are reported in figure 1 show no sharp peaks resulting from crystalline phase and confirms the amorphous nature of the material. 
Table 1 The compositions of target and thin films in atomic\% measured using EDX

\begin{tabular}{|c|c|c|c|c|c|c|}
\hline $\begin{array}{c}\text { Element/Glass thin films } \\
\text { deposited on }\end{array}$ & 0 & $\mathrm{Te}$ & W & $\mathrm{La}$ & $\mathrm{Er}$ & Al \\
\hline Silica substrate at $100^{\circ} \mathrm{C}$ in $\mathrm{O} 2$ & 87.3 & 6.0 & 3.4 & 1.4 & 0.2 & 1.7 \\
\hline Silica substrate at $300^{\circ} \mathrm{C}$ in $\mathrm{O} 2$ & 80.2 & 7.5 & 8.1 & 2.7 & 0.1 & 1.4 \\
\hline $\begin{array}{l}\text { PDMS on silica substrate at } \\
100^{\circ} \mathrm{C} \text { in } \mathrm{O} 2\end{array}$ & 83.8 & 7.6 & 5.8 & 2.3 & 0.2 & 0.3 \\
\hline $\begin{array}{l}\text { PDMS on silica substrate at } \\
100^{\circ} \mathrm{C} \text { in } 96 \mathrm{vol} \% \mathrm{O} 2 / 4 \mathrm{vol} \% \mathrm{He}\end{array}$ & 81.6 & 7.7 & 6.2 & 2.4 & 0.2 & 1.9 \\
\hline Bulk glass & 78.4 & 11.7 & 3.7 & 3.1 & 0.3 & 2.7 \\
\hline
\end{tabular}

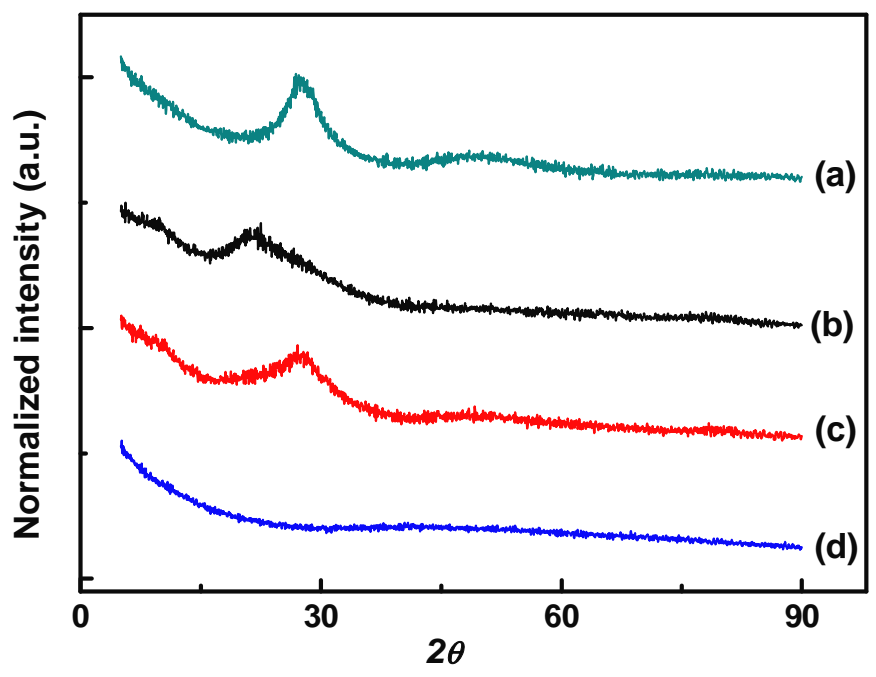

Figure 1. XRD of samples: (a) target glass, (b) glass film on silica deposited at $100^{\circ} \mathrm{C}$, (c) glass film on silica deposited at $300^{\circ} \mathrm{C}$ and (d) glass film on polymer deposited at $100^{\circ} \mathrm{C}$

\subsection{Optical properties and topography of thin films on silica substrates}

All transmittance measurements were measured using a double beam spectrophotometer with bare silica substrate as reference. As shown in figure 2, the transmittance of the thin film deposited at $100^{\circ} \mathrm{C}$ on the silica substrate was as high as $95 \%$, over the range of $650 \mathrm{~nm}$ to $2500 \mathrm{~nm}$. By comparison, the transmittance of the thin films deposited at $300^{\circ} \mathrm{C}$, despite having lower thickness, is seen to be fractionally lower than those fabricated at $100^{\circ} \mathrm{C}$, which is the result of smaller particle clusters 
constituting the film at higher substrate temperature (see figure 3). The interference fringe patterns shown in figure 2 are an indication of thickness uniformity of the films in the measured area.

Figures $3 \mathrm{a}$ and $3 \mathrm{~b}$ show the SEM images of the surface of the films deposited at $100{ }^{\circ} \mathrm{C}$ and $300{ }^{\circ} \mathrm{C}$ respectively. It is apparent that there is no much difference in the film structure, except the nano-scale grain boundaries (dark appearance in the image) per unit area. The particle size on average is much smaller and there is no cracks shown for the $300^{\circ} \mathrm{C}$ deposition while at $100^{\circ} \mathrm{C}$ there is better agglomeration of particles of relatively larger size and fewer cracks at the nanoscale. The comparison of microstructure also confirms the reformation and growth of particulates in the post-plasma plume, which carries a majority of ablated materials through kinetic energy exchange with the gas molecules to the substrate. In addition, several samples has been prepared at $100{ }^{\circ} \mathrm{C}$ and $300{ }^{\circ} \mathrm{C}$ respectively using exactly the same deposition parameters, and the results showed that the topography and optical properties of the thin films deposited at the same conditions were reproducible.

The refractive indices and propagation loss of the thin films deposited at $100^{\circ} \mathrm{C}$ on silica substrates were measured at $633 \mathrm{~nm}$ using the prism coupler, and were found to be 1.80 and $0.2 \mathrm{~dB} / \mathrm{cm}$, respectively. While the thin films deposited at $300^{\circ} \mathrm{C}$ have a higher refractive index of 1.920 and an optical loss of 0.7 $\mathrm{dB} / \mathrm{cm}$. The distinction of refractive index between these two thin films indicates difference density of the thin films [11]. While the difference in loss values observed for two films can be justified by the different refractive index contrast between the thin film and the adjoining silica substrate, and the nanoscale defects on the surface shown in figure 3a, that affect the Rayleigh scattering losses [12-14].

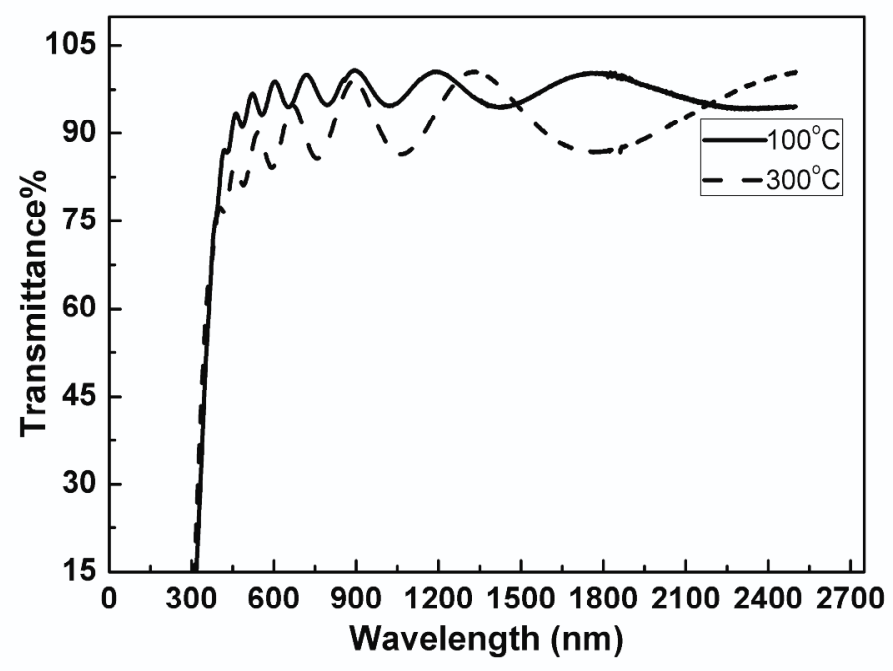

Figure 2: Optical transmittance spectra of the TWL glass thin films deposited on silica substrates in the UV, visible and NIR range. 

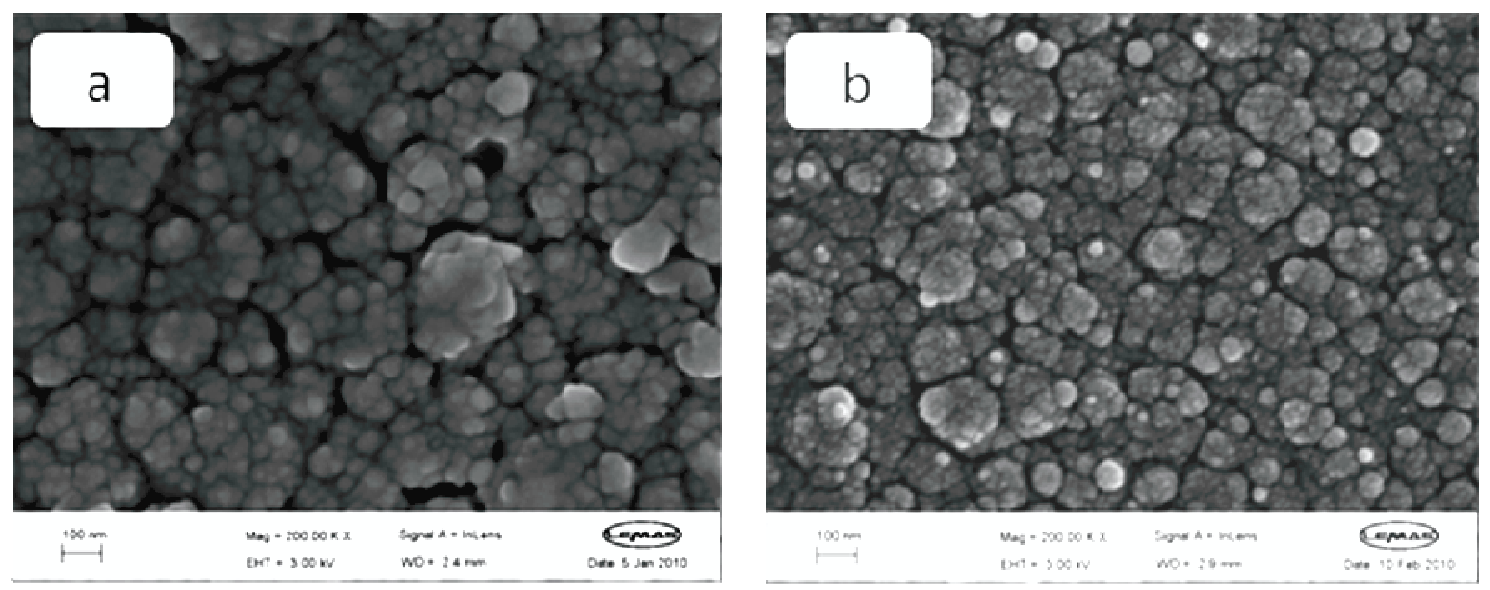

Figure 3: SEM images of a TWL glass thin deposited over silica substrate at (a) $100{ }^{\circ} \mathrm{C}$ and (b) $300{ }^{\circ} \mathrm{C}$

In figure 4, the room temperature fluorescence in the $\mathrm{Er}^{3+}$ :ion doped TWL glass thin films deposited on the silica substrate at $100^{\circ} \mathrm{C}$ and $300^{\circ} \mathrm{C}$ are compared. The spectra were measured using a $980 \mathrm{~nm}$ semiconductor diode laser. The pumping at $980 \mathrm{~nm}$ excites the $\operatorname{Er}^{3+}:{ }^{4} \mathrm{I}_{15 / 2}$ states to a metastable ${ }^{4} \mathrm{I}_{11 / 2}$ state, from which the non-radiative decay occurs and populates the lasing level at ${ }^{4} \mathrm{I}_{13 / 2}$. The line-widths of the ${ }^{4} \mathrm{I}_{13 / 2} \rightarrow{ }^{4} \mathrm{I}_{15 / 2}$ transition in TWL thin films deposited on silica substrates at $100^{\circ} \mathrm{C}$ and $300^{\circ} \mathrm{C}$ have similar shape, and no significant difference in the peak position. The small blue shift $(\sim 3 \mathrm{~nm})$ of the peak of the spectrum of high temperature deposited film compare to that of the film deposited at $100^{\circ} \mathrm{C}$ is within experimental error.

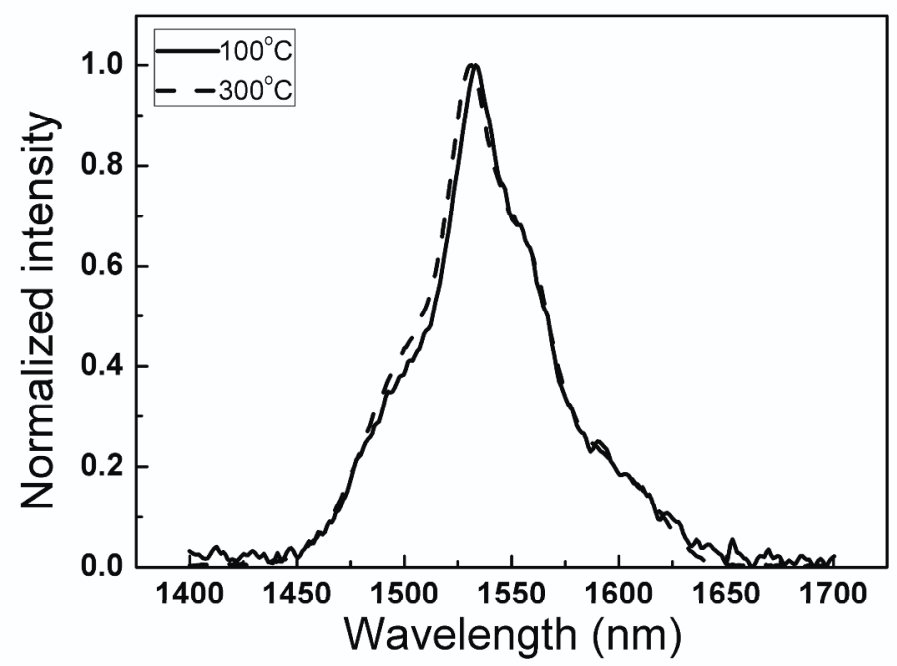

Figure 4: The room temperature PL spectra of the TWL thin films deposited at $100^{\circ} \mathrm{C}$ (solid) and $300^{\circ} \mathrm{C}$ (dashed) 
The values of the fluorescence bandwidth $\left(\Delta \lambda=\int \operatorname{Id} \lambda / I_{\max }\right.$ of two photoluminescence (PL) spectra are reported in table 2 , and the bandwidth of the films deposited at $100^{\circ} \mathrm{C}$ and $300^{\circ} \mathrm{C}$ are the same at $72 \mathrm{~nm}$. The lifetimes of the ${ }^{4} \mathrm{I}_{13 / 2} \rightarrow{ }^{4} \mathrm{I}_{15 / 2}$ transition are also compared as well as the experimental data of the propagation losses, refractive index (at $633 \mathrm{~nm}$ ) and thickness of the films are listed in table 2. And it can be observed that the PL lifetime of the films deposited on silica is lower compared to that of the target. This can be attributed to larger $-\mathrm{OH}$ concentration in the films resulting in increase of the nonradiative relaxation from ${ }^{4} \mathrm{I}_{13 / 2}$ level. The origin of these hydroxyl groups may be from the moisture present in the process gas used during the deposition and the presence of nanoscale grain boundaries also favors moisture adsorption.

Table 2: Optical and spectroscopic properties of TWL bulk glass and thin films deposited on plain and polymer-coated silica substrates

\begin{tabular}{|c|c|c|c|c|c|c|}
\hline $\begin{array}{l}\text { Glass films } \\
\text { deposited on }\end{array}$ & $\begin{array}{c}\text { Gas } \\
\text { atmosphere } \\
\text { for deposition } \\
@ 135 \text { mTorr }\end{array}$ & $\begin{array}{c}\text { Refractive } \\
\text { index at } \\
633 \mathrm{~nm} \\
( \pm 0.0005)\end{array}$ & $\begin{array}{l}\text { Loss at } \\
633 \mathrm{~nm}^{-1} \\
\left(\mathrm{~dB} \mathrm{~cm}^{-1}\right. \\
\pm 0.2)\end{array}$ & $\begin{array}{l}\text { Fluorescence } \\
\text { bandwidth } \\
(\mathrm{nm})\end{array}$ & $\begin{array}{l}\text { Lifetimes } \\
\quad(\mathrm{ms}) \\
{ }^{4} \mathrm{I}_{13 / 2} \rightarrow{ }^{4} \mathrm{I}_{15 / 2} \\
( \pm 0.02)\end{array}$ & $\begin{array}{l}\text { Thickness } \\
\quad(\mu \mathrm{m}) \\
( \pm(0.5 \%+5 \\
\mathrm{nm}))\end{array}$ \\
\hline $\begin{array}{c}\text { Silica } \\
\text { substrate at } \\
100^{\circ} \mathrm{C}\end{array}$ & $\mathrm{O}_{2}$ & 1.8201 & 0.2 & 72 & 2.28 & 1.073 \\
\hline $\begin{array}{c}\text { Silica } \\
\text { substrate at } \\
300^{\circ} \mathrm{C}\end{array}$ & $\mathrm{O}_{2}$ & 1.9213 & 0.7 & 72 & 2.00 & 0.983 \\
\hline $\begin{array}{l}\text { PDMS on } \\
\text { silica substrate } \\
\text { at } 100^{\circ} \mathrm{C}\end{array}$ & $\mathrm{O}_{2}$ & 1.6380 & 1.1 & 69 & 1.24 & 1.698 \\
\hline $\begin{array}{l}\text { PDMS on } \\
\text { silica substrate } \\
\text { at } 100^{\circ} \mathrm{C}\end{array}$ & $\begin{array}{c}96 \text { vol\% } \% \mathrm{O}_{2}-4 \\
\text { vol } \% \mathrm{He}\end{array}$ & 1.8954 & 0.1 & 71 & 1.22 & 0.784 \\
\hline Bulk glass & - & 2.0965 & - & 77 & 5.30 & - \\
\hline
\end{tabular}

\subsection{Optical properties and topography of thin films on PDMS coated on silica substrates}

In our experiments we confined all the TWL glass on polymer-coated substrates deposition to temperatures below $150^{\circ} \mathrm{C}$ to avoid polymer decomposition. Although these materials decompose readily between $300{ }^{\circ} \mathrm{C}-400{ }^{\circ} \mathrm{C}$ [15], under high vacuum environments, such as the one in the PLD chamber, the degradation of polymer structure can take place at even lower temperatures.

For the deposition of thin films on polymer-coated substrates, two different ambient gases were used in the PLD chamber: high purity oxygen and a mixture of 96 vol \% oxygen with 4 vol\% of helium. The 
reason for introducing helium $(\mathrm{He})$ with $\mathrm{O}_{2}$ in the chamber at a comparable partial pressure is that the ionization energy of $\mathrm{He}$ is higher than that of $\mathrm{O}_{2}\left(\mathrm{He}: 24.59 \mathrm{eV}\right.$ and $\left.\mathrm{O}_{2}: 13.62 \mathrm{eV}\right)$, and the high energetic $\mathrm{He}$ species (He radical and $\mathrm{He}$ ions) has the advantage of reducing the roughness of the thin film surface [16]. In figure 5 the SEM images of TWL glass thin films deposited on the PDMS-coat silica substrate are shown. The thin films prepared in $\mathrm{O}_{2}-\mathrm{He}$ atmosphere, shown in figure $5 \mathrm{~b}$ appear to have much denser and finer structures than that deposited in $\mathrm{O}_{2}$ atmosphere, as shown in figure $5 \mathrm{a}$.

The microstructures observed in the SEM images in figure 5 significantly differ from those shown in figures $3 a$ and $3 b$ in terms of number of cracks per unit area. The cracks seen in figure 5 appear to have a width below $50 \mathrm{~nm}$ but are interconnected to a scale of few hundreds of nanometers. It can be concluded from the deposition experiments that the cracking tendency in TWL glass films on silica and PDMS coated silica is strongly dependent on the thermal expansion coefficient of the substrate property, and less on the substrate temperatures and the types of gases used in the deposition process.
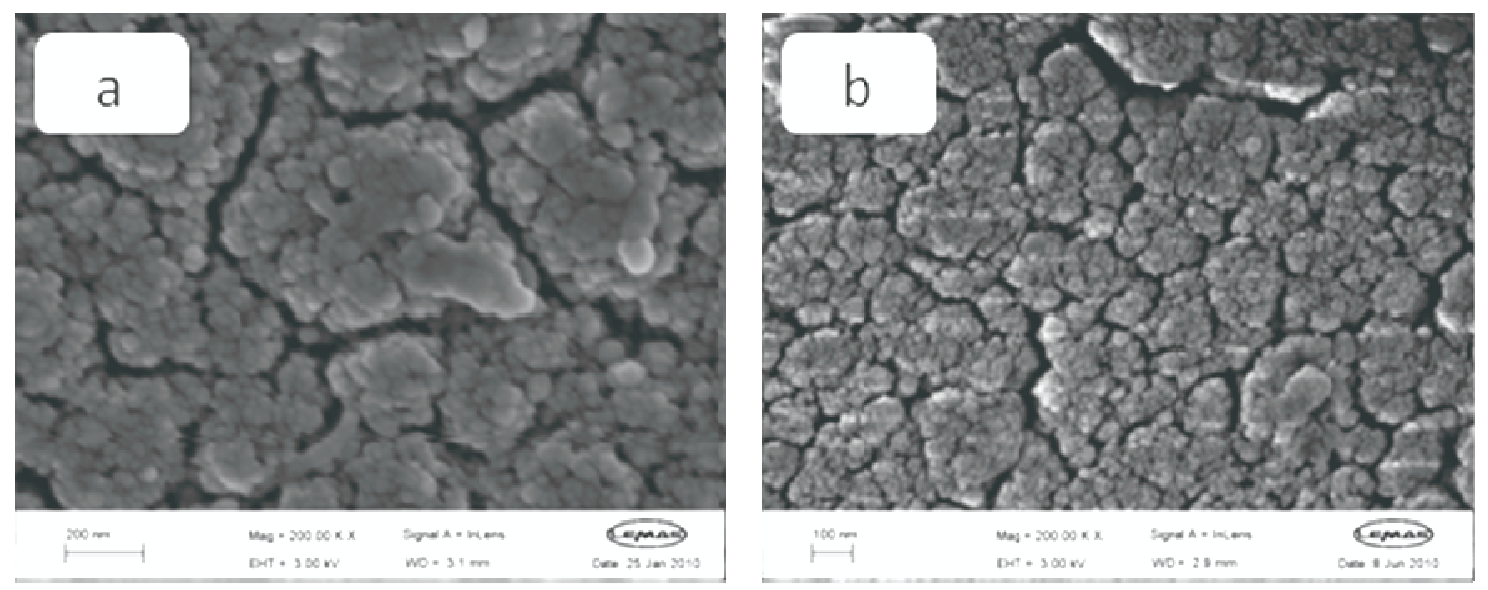

Figure 5: SEM images of TWL glass thin films on polymer substrates: a) at $100^{\circ} \mathrm{C}$ in $\mathrm{O}_{2}$ gas, b) at $100^{\circ} \mathrm{C}$ in a gas mixture of $96 \mathrm{vol} \% \mathrm{O}_{2}$ and $4 \mathrm{vol} \% \mathrm{He}$.

The transmission spectra of TWL glass films on PDMS, formed at $100^{\circ} \mathrm{C}$ in a residual gas of pure oxygen and a mixture of $96 \mathrm{vol} \% \mathrm{O}_{2}$ and $4 \mathrm{vol} \% \mathrm{He}$ are compared in figure 6. The two films exhibit better than $90 \%$ transmittance between $800 \mathrm{~nm}$ and $1600 \mathrm{~nm}$. However, the film deposited with $\mathrm{He} / \mathrm{O}_{2}$ mixture shows marginally better transmission at shorter wavelengths below $800 \mathrm{~nm}$.

The measured refractive index and propagation loss at $633 \mathrm{~nm}$ for these two films on PDMS-coated silica substrates are compared in table 2. The TWL films deposited on PDMS-coated silica have higher refractive index at 1.89 than the films deposited on plain silica substrates alone at 1.82. Since the index of refraction depends significantly on the material density, the comparison of measured refractive indices of the TWL films with bulk glass indicates a lower density for the TWL glass films which can be attributed 
to the fractional porosity in the film due to the presence of nano-scale cracks, shown in figures 3 and figure 5 .

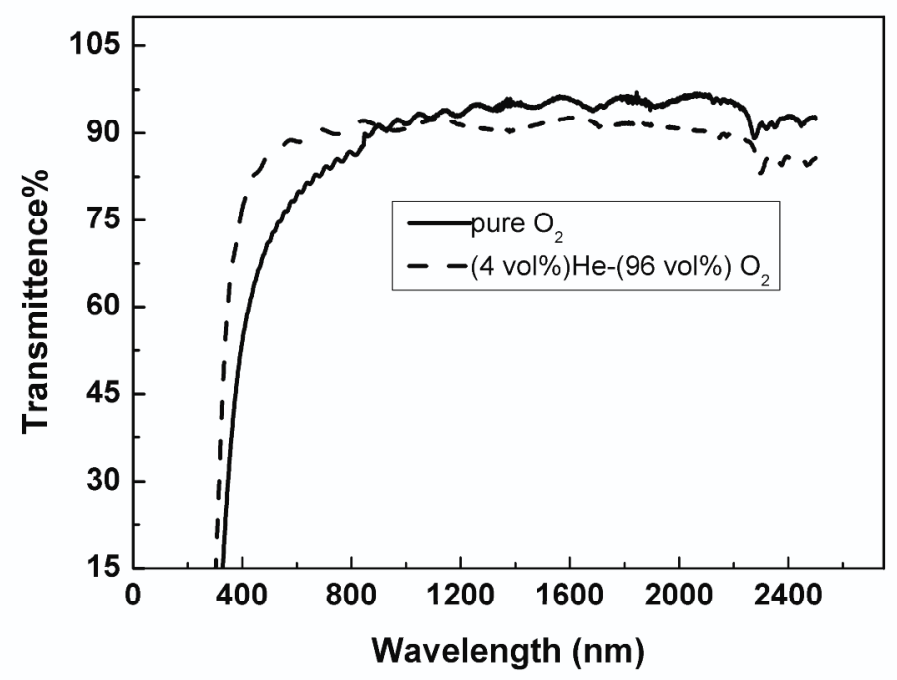

Figure 6: UV-visible-NIR transmittance spectra of the TWL glass thin films deposited in pure oxygen and oxygen/He mixtures on PDMS coated silica substrates

The room temperature photoluminescence spectra of the TWL glass thin films, deposited in oxygen and oxygen-helium mixture are compared in figure 7 . The PL spectra, corresponding to the ${ }^{4} \mathrm{I}_{13 / 2} \rightarrow{ }^{4} \mathrm{I}_{15 / 2}$ transition for $\mathrm{Er}^{3+}$-ions present in the TWL glass, indicate that the two films are structurally similar. The deposited film in the presence of $\mathrm{O}_{2} / \mathrm{He}$ gas, exhibits comparable PL bandwidth with the film deposited in $\mathrm{O}_{2}$ atmosphere, which are $71 \mathrm{~nm}$ and $69 \mathrm{~nm}$, respectively and there is no apparent shift in the peak positions in figure 7 . 


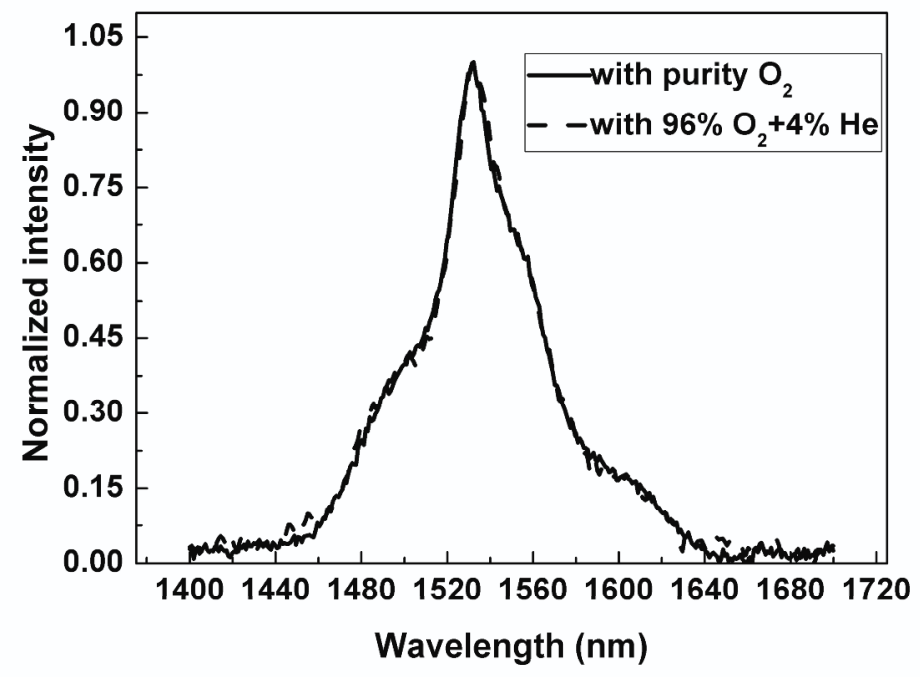

Figure 7: Room temperature PL spectra of TWL glass films, deposited at $100^{\circ} \mathrm{C}$ on PDMS coated silica substrates in $\mathrm{O}_{2}$ and $\mathrm{O}_{2} / \mathrm{He}$ atmospheres.

As shown in table 2, the lifetime of films on polymer have a further reduction in the lifetime compare to that of the thin film on silica, and this may be due to the formation of polymer-rare earth complexes at the polymer-glass interface. To confirm the exact origin of the reduction of the transition lifetime observed in the films deposited on two types of substrates, more detailed investigations are required.

\section{Conclusions}

High-quality TWL glass thin films were fabricated on plain and polymer-coated silica substrates using PLD. The thin films of TWL glass formed at $100^{\circ} \mathrm{C}$ have a propagation loss of $0.21 \mathrm{~dB} / \mathrm{cm}$ while the film on polymer-coated substrate exhibited a lower loss of $0.1 \mathrm{~dB} / \mathrm{cm}$. We found from the refractive index measurements that the higher temperature thin films were much denser than that deposited at $100^{\circ} \mathrm{C}$. The measured PL bandwidth and lifetimes of $\mathrm{Er}^{3+}:{ }^{4} \mathrm{I}_{13 / 2}$ to ${ }^{4} \mathrm{I}_{15 / 2}$ transition in the films are smaller than that in the bulk glass. Further optimization of the deposition conditions is required to improve these spectroscopic properties. The PLD method presented in this paper has potential for use for the fabrication of glass -polymer integrated optical devices with both active and passive functionalities.

\section{Acknowledgements}

The authors acknowledge the financial support from the RCUK for their collaborative Basic Technology project contract numbers (EP/D048672/1, EP/D048982/1) 


\section{References}

[1] DeGroot, J.V., et al., Highly transparent silicone materials. Linear and Nonlinear Optics of Organic Materials, 2004. 5517: p. 116-123.

[2] Bamiedakis, N., et al., Cost-Effective Multimode Polymer Waveguides for High-Speed On-Board Optical Interconnects. Ieee Journal of Quantum Electronics, 2009. 45(4): p. 415-424.

[3] Ma, H., A.K.-Y. Jen, and L.R. Dalton, Polymer-Based Optical Waveguides: Materials, Processing, and Devices. Advanced Materials, 2002. 14(19): p. 1339-1365.

[4] Keil, N., H.H. Yao, and C. Zawadzki, Athermal polarisation-independent arrayed-waveguide grating $(A W G)$ multiplexer using an all-polymer approach. Applied Physics B-Lasers and Optics, 2001. 73(5-6): p. 619-622.

[5] Wong, W.H., E.Y.B. Pun, and K.S. Chan, Er3+-Yb3+ codoped polymeric optical waveguide amplifiers. Applied Physics Letters, 2004. 84(2): p. 176-178.

[6] Le Quang, A.Q., et al., Polymer-based materials for amplification in the telecommunication window: Influence of erbium complex concentration on relevant parameters for the elaboration of waveguide amplifiers around $1550 \mathrm{~nm}$. Optical Materials, 2007. 29(8): p. 941-948.

[7] Yang, J., et al., Nd-Doped Polymer Waveguide Amplifiers. Ieee Journal of Quantum Electronics. 46(7): p. 1043-1050.

[8] Jha, A., S. Shen, and M. Naftaly, Structural origin of spectral broadening of 1.5-mum emission in $E r^{\wedge}\{3+\}$-doped tellurite glasses. Physical Review B, 2000. 62(10): p. 6215.

[9] Jose, G., et al., High Quality Erbium doped Tellurite Glass Films Using Ultrafast Laser Deposition. Icton: 2009 11th International Conference on Transparent Optical Networks, Vols 1 and 2, 2009: p. 1142-1145.

[10] Douglas B. Chrisey, G.K.H., ed. Pulsed Laser Deposition of Thin Film. 1 ed. 1994, John Wiley\& Son Canada. 17.

[11] Caricato, A.P., et al., Er-doped oxyfluoride silicate thin films prepared by pulsed laser deposition. Optical Materials, 2007. 29(9): p. 1166-1170.

[12] Hu, J., et al., Low-loss high-index-contrast planar waveguides with graded-index cladding layers. Opt. Express, 2007. 15(22): p. 14566-14572.

[13] Corsin, B., et al. A New Approach to Light Scattering from Nanotextured Interfaces for Silicon Thin-Film Solar Cells. in Optical Nanostructures for Photovoltaics: Optical Society of America.

[14] Price, P.B. and L. Bergstrã IIm, Enhanced Rayleigh scattering as a signature of nanoscale defects in highly transparent solids. Philosophical Magazine A, 1997. 75(5): p. 1383 - 1390.

[15] Nakade, M., K. Ichihashi, and M. Ogawa, Preparation of titania/PDMS hybrid films and the conversion to porous materials. Journal of Sol-Gel Science and Technology, 2005. 36(3): p. 257264.

[16] Rusop, M., et al., Effect of Helium gas on the deposition of diamond like carbon thin films by pulsed laser ablation. International Journal of Modern Physics B, 2002. 16(6-7): p. 871-875. 